\title{
Advanced Manufacture of Reflectors
}

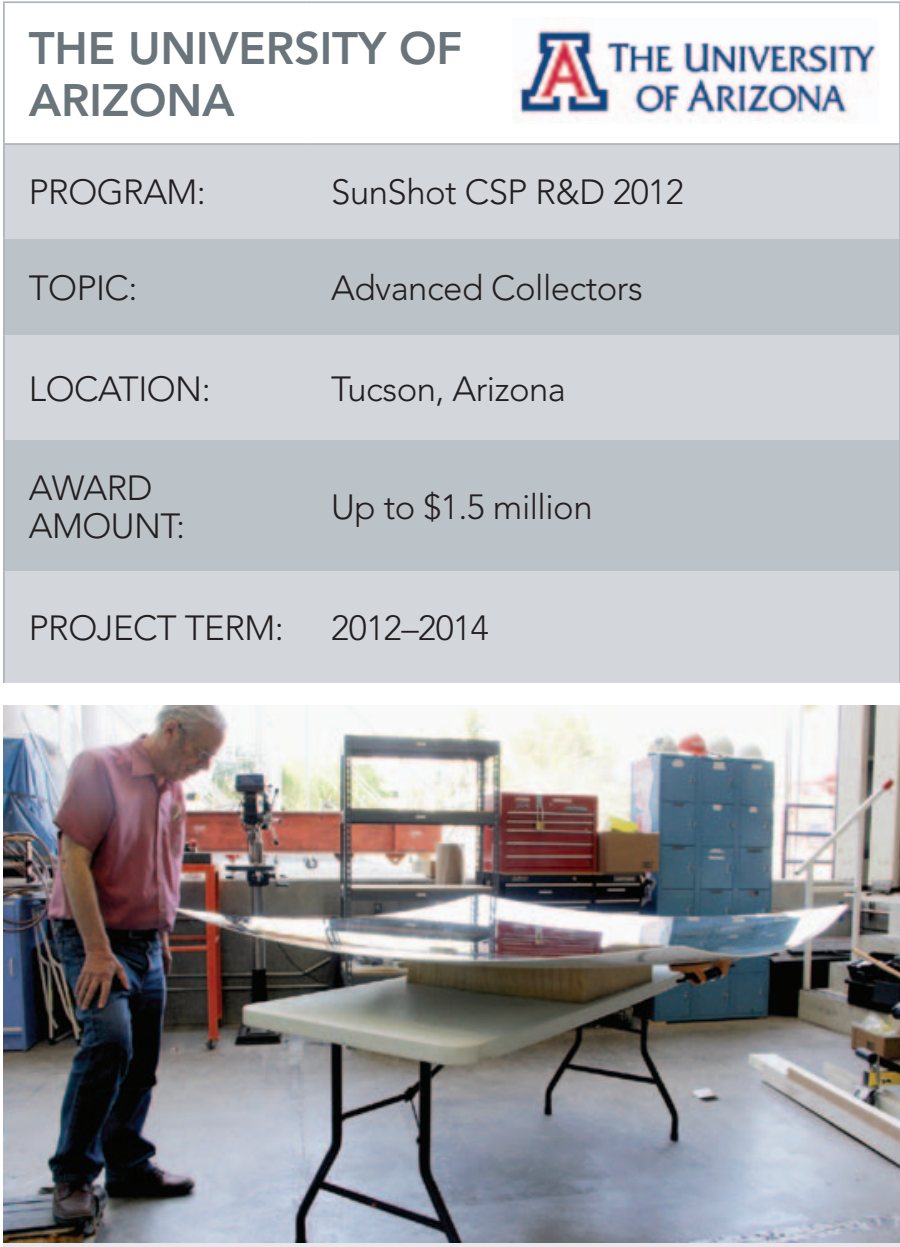

Principal investigator Dr. Roger Angel evaluates a self-supporting second-surface glass reflector made by the new molding process. Photo by The University of Arizona

\section{CONTACTS}

\section{Project Leader:}

Dr. Roger Angel

angelj@email.arizona.edu
Partnering Organizations:

- Rioglass Solar, S.A

- Glasstech, Inc.

\section{MOTIVATION}

Most state-of-the-art reflectors use second-surface silvered glass mirrors carried by lightweight framework structures that track the sun. Though life spans of more than 20 years are already established for this technology, improved manufacturing processes are needed to make reflectors of higher accuracy and in a greater variety of shapes, and to reduce costs of very high-volume production, in line with SunShot targets.

\section{PROJECT DESCRIPTION}

The research team is working to develop a novel method for shaping float glass. The process involves softening and slumping the glass into a full-body mold. To preserve the original high polish of the glass on both front and back surfaces, the high-accuracy mold surface is machined to minimize contact while still yielding the required shape. A new mold with higher accuracy is being obtained for this project. In parallel, the team is boosting short wavelength reflectivity and inhibiting soiling through the use of advanced coatings. This boosting method has already yielded $95 \%$ reflectivity in samples made with glass of very low iron content thus reducing weight.

\section{IMPACT}

The rapid heating and cooling technique developed by this research team can reduce the time required for the shaping step from more than 5 hours to about 200 seconds. By enabling mass production of solar concentrating mirrors at high speed, this project should lead to improved performance and as much as a $40 \%$ reduction in manufacturing costs for reflectors made in very high volume. 